\title{
Educação Ambiental no Bioma Caatinga: formação continuada de professores de escolas públicas de São João do Cariri, Paraíba
}

\author{
Francisco José Pegado Abílio ${ }^{1}$ \\ Hugo da Silva Florentino ${ }^{2}$ \\ Thiago Leite de Melo Ruffo ${ }^{3}$
}

Resumo: A educação ambiental pode propiciar uma nova percepção nas relações entre o homem e a natureza, assim como reforçar a necessidade de o homem agir como cidadão na busca de soluções para problemas locorregionais. A presente pesquisa objetivou promover estratégias de formação continuada de professores tendo como eixo norteador o Bioma Caatinga e as problemáticas ambientais do Rio Taperoá. As atividades estão sendo desenvolvidas com 42 docentes, em intervalos mensais (novembro/2006-abril/2009), em três escolas do município de São João do Cariri - PB. Esta pesquisa é de cunho qualitativo (Pesquisa Etnográfica e Fenomenológica) e nela têm sido desenvolvidas diferentes ações teórico-prático-instrumentais, tais como: análise das concepções dos docentes sobre Meio Ambiente e

${ }^{1}$ Bacharel e licenciado em Ciências Biológicas pela Universidade Federal da Paraíba, doutor em Ciências Naturais pela Universidade Federal de São Carlos, professor associado do Dep. de Metodologia da Educação do Centro de Educação da Universidade Federal da Paraíba. Contato: R. Maria Rosa Padilha, n. 84, Ed. Aeroville, Apart. 210, Bairro Bessa, João Pessoa Paraíba, CEP: 58036-840.E-mail: chicopegado@yahoo.com.br

${ }^{2}$ Licenciado e bacharel em Ciências Biológicas pela Universidade Federal da Paraíba (UFPB), mestrando do Programa Regional de Pós-Graduação em Desenvolvimento e Meio Ambiente (PRODEMA) da UFPB. Professortutor do Curso de Graduação em Ciências Naturais (Licenciatura a Distância), Centro de Educação, UFPB. E-mail: hugosilvaxtr@yahoo.com.br

${ }^{3}$ Bacharel e licenciado em Ciências Biológicas pela Universidade Federal da Paraíba, mestre em Desenvolvimento e Meio Ambiente pelo PRODEMAUFPB. E-mail: thiagoruffo@yahoo.com.br 
EA; oficinas ecopedagógicas; discussões e atividades lúdicas; estudos do meio; exposições científicas e culturais. A partir das ações desenvolvidas com os educadores, percebeu-se que uma grande maioria destes tem atuado de forma intertransdisciplinar, relacionando e discutindo as problemáticas ligadas à Caatinga nas suas disciplinas.

Palavras-chave: Semiárido. Profissionalização Docente. Oficinas Ecopedagógicas.

Abstract: Environmental education can provide a new perception in the relations between man and nature, as well as enhance the necessity for men to act as citizens in the search for solutions for local and regional problems. The objective of this research was to promote strategies for continuing teacher education taking as a guiding axis the Caatinga biome and the environmental problems of the Taperoá River. The activities are being developed with 42 teachers, in monthly intervals (November 2006-April 2009) in three different schools in the city of São João do Cariri - Paraíba. This is a qualitative (ethnographic and phenomenological) research in which different theoretical, practical and instrumental actions have been developed, such as: analysis of teachers' conceptions of Environment and Environmental Education; eco-educational workshops; discussions and recreational activities; studies of the environment; scientific and cultural exhibitions. From the actions developed so far with the educators it was possible to realize that most of them have been acting in an inter-transdisciplinary way, referring to and discussing the problems related to Caatinga in their disciplines.

Keywords: Semiarid. Teacher education. Eco-educational workshops.

\section{Introdução}

A incorporação da questão ambiental no cotidiano das pessoas pode propiciar uma nova percepção das relações entre o ser humano, a sociedade e a natureza e promover uma reavaliação de valores e atitudes na convivência coletiva e individual, assim como reforçar a necessidade de ser e agir como cidadão na busca de soluções para 
problemas ambientais locais e nacionais que prejudiquem a qualidade de vida (DIAS, 2003; SATO, 2001).

Nesse contexto, a escola é um local propício para o desenvolvimento de projetos com enfoque educativo e relacionado ao ambiente em que vivemos (MANZANO; DINIZ, 2004), pois facilita o envolvimento de membros de todos os níveis de uma sociedade. A ideia é que professores e alunos exerçam sua cidadania em relação aos seus direitos e deveres para com o meio ambiente em que vivem (ABÍLIO; GUERRA, 2005b).

É fundamental o estabelecimento de políticas públicas que fortaleçam as escolas de educação básica em virtude da importância que estas exercem no processo de formação social, cultural, humana e ética da sociedade. Mesmo tendo alcançado grandes avanços, no que se refere aos seus objetivos, conteúdos, estratégias metodológicas e materiais didáticos, o universo escolar ainda necessita de caminhos que lhe permitam contemplar dimensões relevantes do conhecimento. Dimensões essas que, muitas vezes, são enfraquecidas pela ênfase no tecnicismo e pela falta de uma formação holística que inter-relacione as diferentes potencialidades do ser humano.

Os movimentos de reforma educativa da última década têm contribuído para o estudo da qualidade do processo de ensinoaprendizagem, e muitos investigadores focalizam a capacidade docente e a necessidade de tornar mais atraente e prazerosa a prática pedagógica, tanto para educadores quanto para educandos (ZABALA, 1998), portanto, deve-se adequar o ensino a essa realidade e incentivar os professores a serem praticantes da investigação em suas aulas, estabelecendo-se um sentido maior de valor e dignidade à prática docente.

Faz-se necessário, então, considerar e usar as constatações dos professores para organizarmos uma nova ação educativa que venha a resolver ou amenizar os problemas que o homem tem em relação ao ambiente, de tal forma a satisfazer melhor os interesses do professor para que ele possa, junto aos seus alunos, perceber o mundo em que vivem, melhorando assim suas próprias vidas.

No entanto, a falta de integração interdisciplinar é fonte de grandes dificuldades no planejamento e aprendizado dos conteúdos 
referentes ao Meio Ambiente e à Educação Ambiental (BRASIL, 1998). Os professores de ensino fundamental e médio precisam buscar alternativas e/ou instrumentos para desenvolver esses conteúdos no seu cotidiano escolar com o intuito de promover um aprendizado significativo (GUERRA; ABÍLIO, 2005, GUERRA; ABÍLIO, 2006).

A reprofissionalização ou atualização de professores e a revisão de suas práticas e conceitos referentes à temática ambiental se fazem necessárias. Assim, uma formação continuada desses professores é absolutamente urgente, lado a lado com a recomposição dos cursos de formação inicial (ABÍLIO; GUERRA, 2005a). Além disso, será preciso acompanhar e avaliar a evolução dos projetos e programas voltados para essa finalidade a fim de que seja possível estabelecer iniciativas de cooperação educacional que, tendo por base a experiência vivida, tornem-se crescentemente eficazes e permanentes (MENEZES, 2001).

\subsection{O bioma Caatinga e o semiárido paraibano}

Com uma população de cerca de 44 milhões de habitantes, o Nordeste brasileiro é considerado como uma região-problema. No Nordeste seco estão assentadas cerca de 23 milhões de pessoas, sendo este considerado uma das regiões semiáridas mais populosas do mundo (ABÍLIO, 2010). A vegetação é típica de Caatinga, onde os índices pluviométricos são inferiores a $500 \mathrm{~mm}$ por ano e vem sendo observado um processo crescente de desertificação, resultante da utilização de práticas agropecuárias não adequadas e do desmatamento desenfreado da vegetação.

A Caatinga é um bioma exclusivamente brasileiro que cobre quase 10\% do território nacional (CASTRO et al., 2006) e sofre forte pressão antrópica na forma de queimadas, desmatamentos e caça, o que gera sua fragmentação e a redução de habitats. Por muito tempo foi tratado, erroneamente, como um ambiente de pouca riqueza biológica. Entretanto, quando comparada a outras regiões semiáridas do mundo, a Caatinga apresenta um alto grau de diversidade biológica (LEAL et al., 2005; MENDES, 1997), onde é possível encontrar altas taxas de endemismo, estimando-se que pelo menos $40 \%$ das espécies da flora identificadas sejam endêmicas desse bioma. Diante disso, a implementação de atividades de sensibilização ambiental nos diferentes 
espaços educativos (formal, informal e não formal) pode contribuir para o conhecimento da biodiversidade locorregional e a consequente conservação desta.

O Cariri paraibano, onde este projeto foi desenvolvido, apresenta um quadro de atraso econômico e social muito grave, assim como uma destruição desenfreada do bioma Caatinga, determinada pela estagnação ou declínio das atividades produtivas tradicionais. De fato, a produção agropecuária nessa região vem caindo gradativamente, com perdas de competitividade em relação a outros centros produtores (MENDES, 1997) e com consequente migração da população humana para outras regiões.

O problema socioeconômico-ambiental no Cariri paraibano ainda é grave, mas apenas o abandono das atividades agropecuárias intensivas não seria necessário para a recuperação do bioma e a conservação de sua biocenose. Além de projetos de educação ambiental e de políticas públicas, seria necessário nessa região: reflorestar as áreas degradadas, criando um ambiente propício para a regeneração e reestruturação do solo erodido; ampliar a utilização de técnicas agrícolas familiares e não produzir queimadas; utilizar o solo e implementar projetos de irrigação somente após a realização de estudos prévios de impactos ambientais (EIA-RIMA); fiscalizar de forma mais intensiva e efetiva a retirada de madeira para fins energéticos e outros fins, de modo a só ser permitido o manejo sustentável em algumas áreas; ampliar o número de unidades de conservação no bioma, entre outras ações que venham a contribuir para a conservação da biodiversidade local.

A leitura sobre o ambiente, por analogia, nos leva a conhecê-lo, mas nem sempre a participar das ações de manutenção do equilíbrio ecológico do bioma em que residimos. Observar como os diferentes grupos sociais se comportam e investigar as relações que os mesmos mantêm com o ambiente em que vivem, enfim, construir com a sociedade maneiras de lidar com as problemáticas ambientais deve ser a base para o desenvolvimento de políticas educacionais que abordem o tripé Sociedade-Participação-Meio Ambiente (PENTEADO, 2000).

O efeito combinado entre as condições climáticas próprias da região semiárida paraibana e as práticas inadequadas de uso e aproveitamento do solo e dos demais recursos naturais tem acentuado 
o desgaste da paisagem natural, levando à perda da biodiversidade e ao esgotamento de recursos naturais, além de acentuar o processo de desertificação nas áreas susceptíveis. Buscar a conservação pela gestão não é algo facilmente executável, principalmente quando as propostas de intervenção apresentadas se contrapõem aos padrões comportamentais da comunidade (GADOT'TI, 2000).

Compreender as questões ambientais para além de suas dimensões biológicas, químicas e físicas, ou seja, como questões sociopolíticas, exige a formação de uma consciência ambiental e a preparação para o pleno exercício da cidadania, fundamentadas nos conhecimentos prévios dos atores sociais que se utilizam dos ecossistemas do seu entorno (ABÍLIO et al., 2005). A implementação de projetos e vivências educativas integradoras no contexto da educação básica pode contribuir para a mudança de atitudes e comportamentos dos diferentes grupos sociais inseridos no bioma Caatinga, propiciando uma elevação do nível de consciência dos mesmos (ABÍLIO et al., 2010).

Nessa perspectiva, este trabalho teve como objetivo geral promover estratégias de formação continuada dos professores do ensino fundamental e médio do município de São João do Cariri, PB, através da Educação Ambiental, tendo como eixo norteador o bioma Caatinga e a Bacia Hidrográfica do Rio Taperoá.

\section{Percurso metodológico}

O trabalho se caracteriza como uma pesquisa de cunho qualitativo na qual se utilizaram como pressupostos teóricometodológicos elementos da Etnografia Escolar, da Fenomenologia e da Teoria do Biorregionalismo.

O Método Etnográfico é uma modalidade de investigação naturalista que tem como base a observação e a descrição, a partir das quais pretende descrever, explicar e interpretar a cultura. Outro ponto importante é seguir certas normas básicas, como deixar de lado preconceitos e estereótipos e agir como participante, assim como questionar sobre o que parece comum e observar os tipos de relações encontradas no meio ambiente (MARCONI; LAKATOS, 2004). 
A Pesquisa Fenomenológica, como afirma Sato (2001), trabalha com os significados das experiências de vida sobre uma determinada concepção ou fenômeno, explorando a estrutura da consciência humana (PASSOS; SATO, 2005). A Fenomenologia ressalta a ideia de que o mundo é criado pela consciência, o que implica o reconhecimento da importância do sujeito no processo da construção do conhecimento (GIL, 1999). O Método Fenomenológico é descritivo e analisa dados inerentes à consciência e não especula sobre cosmovisões, isto é, funda-se na essência dos fenômenos e na subjetividade transcendental, pois as essências só existem na consciência (MOREIRA, 2004).

O Biorregionalismo é uma tentativa de resgatar uma conexão intrínseca entre comunidades humanas e a comunidade biótica de uma dada realidade geográfica. Os critérios para definir as fronteiras de tais regiões podem incluir similaridades do tipo de terra, flora, fauna ou bacia hidrográfica. A recuperação histórica, simbólica e cultural apregoa valores de cooperação, solidariedade e participação, permitindo desenvolvimento entre a comunidade e o meio biofísico (SATO, 2001). O Biorregionalismo busca o conhecimento local através das análises biológicas e narrativas da região, estimulando e intervindo para que a própria comunidade possa ser autônoma nos processos de conservação do ambiente e implementação dos programas de Educação Ambiental (SATO; PASSOS, 2002).

Para a implementação das metas propostas neste trabalho foram levantadas imagens da realidade sobre a Educação Ambiental, o bioma Caatinga e a problemática da Bacia Hidrográfica do Rio Taperoá na região semiárida paraibana, em três escolas de ensino fundamental e médio do município de São João do Cariri. Procurou-se coletar, questionar, interpretar e relatar dados a fim de diagnosticar a prática pedagógica dos professores e a realidade do entorno escolar, buscandose orientar e fornecer suporte teórico-metodológico aos docentes e contribuir não só para a melhoria das condições do processo ensino aprendizagem no âmbito escolar mas também para o exercício da pesquisa e da cidadania. Foram desenvolvidos, no período de novembro de 2006 a abril de 2009, os seguintes procedimentos teórico-prático-metodológicos: 


\subsection{Diagnóstico e análise da prática educativa dos professores:}

Utilizando-se a observação participante, foram aplicados questionários estruturados com questões dissertativas acerca das condições de trabalho e do perfil dos docentes, o que possibilitou diagnosticar os principais problemas e definir as potencialidades da escola. As metodologias e técnicas de ensino empregadas pelos professores na sua prática pedagógica em relação à temática ambiental, ao bioma Caatinga e à problemática do Rio Taperoá foram analisadas e incentivadas com respeito à produção de novos materiais, visando contribuir para a construção de conhecimentos significativos que pudessem ser utilizados na sua prática pedagógica. Participaram da pesquisa 31 professores do $6^{\circ}$ ao $9^{\circ}$ ano do ensino fundamental e as turmas do ensino médio da EEEFM José Leal Ramos e 11 professores do $2^{\circ}$ ao $5^{\circ}$ ano do ensino fundamental de duas escolas, a Tertuliano de Brito e a Nossa Senhora dos Milagres (São João do Cariri - PB). Para a análise do diagnóstico fenomenológico das concepções de Meio Ambiente e Educação Ambiental utilizaram-se os critérios estabelecidos por Guerra e Abílio (2006), Sato (2001) e Sauvé (1997, 2005).

\subsection{Exposição dialógica e oficinas ecopedagógicas:}

Foram desenvolvidos momentos de exposição-discussão com as seguintes temáticas: "O Ecossistema Caatinga"; "Convivência e Desenvolvimento Sustentável no Semiárido Paraibano"; "Modalidades e Recursos Didáticos para Atividades de Educação Ambiental na Caatinga"; "Biodiversidade na Bacia Hidrográfica do Rio Taperoá"; "Pedagogia de Projetos e EA". Ao longo da implementação das atividades, foram desenvolvidas as seguintes oficinas de produção de conhecimentos e materiais didáticos: Oficina 1 - Bioma Caatinga: Leitura de Imagens; Leitura da Paisagem; Excursão Didática e Estudos do Meio; Oficina 2 - Modelos Tridimensionais em Estudos da Bacia Hidrográfica do Rio Taperoá; Oficina 3 - Fauna e Flora da Caatinga: uso de vídeos e músicas; preparação de jogos didáticos e de álbum seriados; exposição de fotografias, desenhos e pranchas das imagens da Caatinga; Oficina 4 - Relação Homem-Sociedade-Natureza no Bioma 
Caatinga: confecção de bonecos de fantoches para atividades de Educação Ambiental; Oficina 5 - Mitos e Fábulas do Cariri: reconstruindo a identidade cultural no bioma Caatinga a partir dos relatos dos alunos e professores; Oficina 6 - Dramatização: preparação de esquetes teatrais como instrumento de sensibilização de atividades com Educação Ambiental no semiárido. Os textos, poemas, cordéis e os relatos dos mitos e fábulas sobre a Caatinga no Cariri paraibano foram utilizados como roteiro para a produção dos espetáculos teatrais.

\subsection{Exposição científico-cultural:}

Foram realizadas duas exposições científicas (feiras de ciências), a primeira em dezembro de 2007 e a segunda em dezembro de 2008. Todo o material produzido pelos professores e seus alunos foi exposto durante dois dias, recebendo visitas de toda a comunidade escolar e da população da cidade de São João do Cariri.

\section{Resultados e discussão}

O projeto iniciou-se com uma análise prévia dos conhecimentos dos docentes sobre as problemáticas ambientais do bioma Caatinga e do Rio Taperoá e as suas concepções de Meio Ambiente e Educação Ambiental, a partir da aplicação de questionários estruturados, em novembro de 2006. No mesmo dia da aplicação dos questionários, a equipe de Educação Ambiental vinculada ao "Projeto PELD/CNPq: Bioma Caatinga - estrutura e funcionamento" ministrou a palestra educativa "Bioma Caatinga: características e importância" com a presença de todos os alunos, professores e equipe administrativa das escolas.

\subsection{Análise das concepções de Meio Ambiente e Educação Ambiental dos docentes}

O pensamento crítico é necessário não apenas para compreendermos melhor os problemas ambientais mas também para questionarmos nossa própria relação com o meio ambiente, nossas concepções, valores, posições e condutas (SAUVÉ, 1997, 2005). O exercício do pensamento crítico põe em questão as realidades e as 
opções pessoais e sociais em relação ao meio ambiente e propicia a busca da transformação ou melhora e uma organização coletiva mais eficaz, pois nos enriquecemos quando compartilhamos e confrontamos os saberes, as ideias e os valores de cada um (SAUVÉ, 2000).

Como a prática da Educação Ambiental está diretamente relacionada à forma como os atores sociais daquela comunidade percebem o Meio Ambiente, é de crucial importância que sejam conhecidas as representações acerca do Meio Ambiente que esses atores apresentam (TRAVASSOS, 2006).

Com relação às concepções de Meio Ambiente dos docentes, observou-se que estes, em sua maioria - tanto os professores das escolas do $2^{\circ}$ ao $5^{\circ}$ ano $(63,64 \%)$ como os do $6^{\circ}$ ao $9^{\circ}$ ano do ensino fundamental e dos 3 anos do ensino médio (59,26\%) - percebem o ambiente como "Meio de Vida/Lugar para Viver". Segundo Sato (2001), a concepção Meio de Vida é caracterizada por "tudo [o] que nos rodeia, 'oikes', lugar de trabalho e estudos, vida cotidiana". De fato, muitos dos docentes conceituaram meio ambiente como o lugar onde vivem.

Em um projeto desenvolvido em cinco escolas da rede pública do município de Cabedelo - PB, Guerra e Abílio (2006) também constataram que a maioria dos docentes percebia o meio ambiente como lugar para viver, imbuídos de uma visão naturalista. O que se pode afirmar, então, é que houve uma similaridade entre as concepções dos docentes da educação básica que residem no bioma Caatinga e os da região litorânea, que apresentam, primordialmente, uma visão de meio ambiente como lugar para viver.

Bezerra e Gonçalves (2007), trabalhando com a concepção de professores no estado de Pernambuco, também constataram que a maioria deles apresenta uma concepção naturalista de meio ambiente. Esse tipo de representação social dos professores é enfatizado por Reigota (1998, p. 74), que afirma que, "no momento em que solicita do professor uma definição pessoal de meio ambiente, quase todos possuem uma representação 'naturalista', ou seja, a definição de meio ambiente pode ser considerada como sinônimo de natureza”.

A Política Nacional de Meio Ambiente (Lei n 6.938, de 31 de agosto de 1981) conceitua meio ambiente como o conjunto de 
condições, leis, influências e interações de ordem física, química e biológica que permite, abriga e rege a vida em todas as suas formas (BRASIL, 1981). No entanto, Lima-e-Silva et al. (2002) definem ambiente como o conjunto de fatores naturais, sociais e culturais que envolvem um indivíduo e com os quais ele interage, influenciando e sendo influenciado por eles.

Nesse sentido, há uma necessidade de desenvolver ações nas escolas para que os diferentes atores sociais possam analisar as relações Homem-Natureza-Sociedade sem dissociá-las das condições abióticas e bióticas dos ecossistemas onde estão inseridos.

De fato, como afirma Reigota (1998), mais do que informações e conceitos, a escola deve se propor a trabalhar com atitudes, com formação de valores, com o ensino e a aprendizagem de habilidades e procedimentos, o que é, sem dúvida, um grande desafio para a educação.

Com relação às concepções de Educação Ambiental dos docentes das escolas do $2^{\circ}$ ao $5^{\circ}$ ano, estes consideram-na como "prática educativa" (45,46\%), seguindo-se de uma visão "conservacionista". Já os professores do $6^{\circ}$ ao $9^{\circ}$ ano do ensino fundamental e dos 3 anos do ensino médio definem EA tanto como "prática educativa" quanto como processo de "sensibilizaçãoconscientização", ambos com 25,8\%. Por outro lado, se analisarmos/somarmos as visões preservacionistas e conservacionistas, perceberemos uma porcentagem superior a $25 \%$ do total das concepções dos docentes.

Estas informações corroboram aquelas que Segura (2001) constatou em professores de escolas públicas de São Paulo, que também apresentavam concepções preservacionistas, afirmando que as atividades de EA têm como objetivo "preservar a natureza e conscientizar para preservar". Já Travassos (2006) percebeu que, quando questionados sobre a EA, as idéias centrais dos professores de Minas Gerais estavam voltadas ao entendimento desta como forma de preservação do meio ambiente ou como forma de se criar uma consciência ecológica, despertando a necessidade de se promoverem estratégias para a manutenção sustentável da vida. De modo semelhante, Carneiro (2007) constatou que a maioria dos docentes de ensino fundamental ( $2^{\circ}$ a $9^{\circ}$ ano) de escolas públicas de Curitiba 
associava a EA a práticas conservacionistas (49,5\% do total de professores pesquisados). Guerra (2007), em estudo realizado em uma escola pública de Santa Rita - PB, também constatou a visão preservacionista dos docentes, os quais em sua maioria afirmavam que a EA estuda as relações do homem com a natureza, buscando a preservação.

Com base nas falas dos professores das três escolas públicas de São João do Cariri-PB e retomando-se a terminologia de Sauvé (2005), pode-se enquadrar a concepção destes sobre EA na corrente conservacionista. Para a autora, a noção de corrente refere-se à perspectiva teórico-metodológica, ou seja, uma maneira geral de conceber e praticar Educação Ambiental. No entanto, pode se incorporar a uma mesma corrente uma pluralidade de proposições. Por outro lado, uma mesma proposição pode corresponder a duas ou três correntes, segundo o ângulo do qual é analisada (SAUVÉ, 2005). Embora cada uma das correntes apresente um conjunto de características específicas que a distingue das outras, Sauvé afirma que as correntes não são mutuamente excludentes em todos os planos, uma vez que certas correntes compartilham características comuns. $\mathrm{Na}$ conceituação organizada pela autora, as concepções atribuídas a algumas correntes, como, por exemplo, a naturalista e a conservacionista, são muito próximas.

Nesse contexto, é essencial que os professores reconheçam que a atividade docente vai além de clarificações de conceitos e do domínio dos conteúdos específicos e, portanto, incorporem em sua práxis valores humanistas, éticos, conhecimento interdisciplinar e compromisso político. Estes se configuram como um dos maiores desafios para o desenvolvimento da Educação Ambiental na escola básica (LOZANO; MUCCI, 2005).

De fato, como afirmam Pereira e Guerra (2008), nas atividades de formação de professores, numa perspectiva ambiental, há a necessidade de desenvolver uma educação voltada para a transformação do indivíduo construtor de uma sociedade participante e crítica, possibilitando que ele vivencie em suas práticas educativas ações integradas e interdisciplinares que contribuam para a construção do conhecimento científico e que resgatem a história de vida dos educandos numa perspectiva locorregional. 
Portanto, a parceria e a cooperação dos docentes das diferentes disciplinas escolares na implementação de projetos de Educação Ambiental são essenciais para uma mudança de valores e atitudes em relação ao ambiente onde vivem. Como afirma Sauvé (2000), interagir com o meio ambiente requer uma atitude democrática e de colaboração entre os diferentes atores sociais.

Entre os docentes que fizeram parte da pesquisa, um percentual de $23,11 \%$ afirmou que a EA é uma "disciplina escolar". No entanto, a Lei de Diretrizes e Bases da Educação (Lei n. 9.394) ponderou que a EA deve ser considerada em todos os conteúdos curriculares de todos os níveis de ensino, "mas sem constituir disciplina especifica, implicando desenvolvimento de bábitos $e$ atitudes sadias de conservação ambiental e respeito à natureza, a partir do cotidiano da vida, da escola e da sociedade" (BRASIL, 1996).

A Política Nacional de Educação Ambiental (PNEA), instituída em 1999 através da Lei 9.795, dispõe que a EA não deve estar incluída como uma disciplina específica no currículo de ensino, sendo considerada um tema transversal, permeando os conteúdos curriculares das disciplinas, os Parâmetros Curriculares Nacionais (PCNs). A lei também indica que a EA deve ser "desenvolvida como uma prática educativa e integrada, continua e permanente em todos os niveis e modalidade do ensino formal" (BRASIL, 1999). Como afirma Travassos (2006, p. 12), a Educação Ambiental "tem que ser desenvolvida como uma 'prática', para a qual todas as pessoas que trabalham em uma escola precisam estar preparadas. Não basta que seja acrescentada como 'mais uma disciplina' dentro da estrutura curricular".

\subsection{Oficinas ecopedagógicas sobre o bioma Caatinga e o Rio Taperoá}

As Oficinas Ecopedagógicas foram realizadas em 2007, com intervalos mensais, tendo uma duração de 4 horas/aula, com exceção da oficina "A sensibilização ambiental através da dramatização: o teatro de bonecos", que teve duração de 8 horas. Os temas abordados nas oficinas foram: as problemáticas ambientais da Bacia Hidrográfica do Rio Taperoá: construção de um modelo tridimensional (fevereiro/2007); leitura de imagens, da paisagem e estudos do meio (março/2007); biodiversidade: fauna e flora da Caatinga (abril/2007); a 
sensibilização ambiental através da dramatização: o teatro de bonecos (junho/2007); a relação Homem- - Sociedade-Natureza (agosto/2007).

Durante a execução das oficinas foram produzidos materiais inovadores que a posteriori foram utilizados nas aulas dos professores, em diferentes disciplinas, e hoje constituem um acervo de material didático das escolas.

A partir do trabalho realizado pela equipe do PELD/CNPq junto aos docentes, em paralelo à incorporação das temáticas abordadas na prática pedagógica cotidiana destes, foram realizadas, respectivamente nos meses de setembro e novembro de 2007, duas atividades que contaram com a participação de toda a comunidade escolar: uma caminhada ecológica, com o plantio de 200 mudas de plantas nativas da Caatinga, e a I Exposição Científica e Cultural. Nessas atividades houve também a participação da comunidade local, uma vez que esta deve estar em consonância com as atividades escolares. É importante registrar que foi produzido um espetáculo teatral, intitulado "As Pelejas de Mané Caatingueira nas terras do Alagamar", sendo o elenco formado por alunos da escola. O texto do espetáculo discutia problemáticas do bioma Caatinga e fazia um resgate da cultura do Cariri paraibano. Esse texto serviu de base para a Cartilha Pedagógica, que está em fase final de produção e será publicada pela editora da UFPB e aplicada nas escolas inseridas na Bacia Hidrográfica do Rio Taperoá, semiárido paraibano.

Devemos levar em consideração que a formação do professor pode ser entendida como a busca constante do conhecimento, de uma base que poderá se tornar continuada caso assuma um caráter de aperfeiçoamento ao longo da vida profissional para estabelecer competências, as quais podem ser entendidas como um saber fazer derivado das relações entre o conhecimento adquirido em constante diálogo com a prática e com a reflexão pedagógica (GASQUE; GONÇALVES; COSTA, 2003).

É importante enfatizar que, paralelamente às atividades de formação continuada realizadas com os educadores, foram desenvolvidos quatro projetos nas escolas, nos anos de 2007 e 2008, com os alunos, sob nossa orientação, a saber: um projeto de Iniciação Científica-PELD/CNPq (atividades vivenciais como instrumento de 
sensibilização para a conservação da biodiversidade da Caatinga, desenvolvido nas turmas de $7^{\circ}$ ano do ensino fundamental e $2^{\circ}$ ano do ensino médio); um projeto $\mathrm{PIBIC} / \mathrm{CNPq} / \mathrm{UFPB}$ e um projeto POLICEN/UFPB (Projetos de Licenciatura) (atividades desenvolvidas com as turmas de $5^{\circ}$ ano do ensino fundamental de duas escolas); e um projeto PROBEX-SIEX (projeto de extensão desenvolvido com turmas de Educação de Jovens e Adultos - EJA).

A formação continuada de professores da educação básica nunca foi tão necessária como atualmente no Brasil. Os Centros de Formação de Docentes voltados ao fomento da educação e ao aperfeiçoamento permanente dos professores definharam ao longo dos últimos 15 anos, por falta de recursos e de renovação de seus quadros científico-pedagógicos (MENEZES, 2001). Nesse sentido, é necessário refletir sobre a formação inicial dos nossos futuros docentes e que as universidades venham a contribuir de fato para a formação de professores conscientes e críticos de sua prática educativa, de modo que os mesmos possam refletir sobre sua ação pedagógica na busca de um aprendizado significativo (ABÍLIO; CAMAROTTI; SILVA, 2010).

Durante o ano de 2008, com atividades mensais ( 8 horas, aos sábados), foi ministrada a disciplina EA vinculada ao mestrado do PRODEMA (Pós-Graduação em Desenvolvimento e Meio Ambiente) da UFPB, sendo os professores matriculados como alunos especiais do mestrado. O curso teve como ementa: o Conhecimento Científico e sua contribuição à civilização; as bases da Educação Ambiental: suas relações com as Ciências Naturais e as Ciências Sociais; a dimensão universal da Educação Ambiental; a contribuição da Educação Ambiental à conservação dos recursos naturais dos nossos ecossistemas e ao desenvolvimento sustentável; da sensibilização e conscientização à ação prática: suas aplicações nas atividades do ser humano nas zonas urbana e rural.

Em dezembro de 2008 foi realizada a II Exposição Científica e Cultural das escolas com a divulgação dos trabalhos produzidos e no ano de 2009 iniciamos a implementação do Projeto Universal/CNPq, que teve como meta principal ampliar as ações teórico-práticas de formação continuada dos docentes das três escolas do município de São João do Cariri - PB. 
No desenvolvimento desse processo educativo, foi necessário mostrar ao nosso grupo de educadores como o meio ambiente reage às nossas ações. Para essa compreensão, traçamos experiências de participação social que propiciaram a vivência de comportamentos individuais e coletivos, assim como provocaram o desenvolvimento de novas habilidades e competências no desenvolvimento da temática ambiental na educação básica. Nesse processo foi preciso então considerar e usar as constatações dos professores para organizar uma nova ação educativa que contribuísse para minimizar os problemas relacionados ao ambiente em que vivem, de tal forma a satisfazer melhor os seus interesses para que possam, junto aos seus alunos, perceber o mundo em que vivem, melhorando assim suas próprias vidas.

O processo todo evidenciou, portanto, a necessidade de se buscar o desenvolvimento da cidadania e a formação da consciência ambiental dentro da escola, sendo esta o local adequado para a realização de um processo de ensino e aprendizagem ativo e participativo. Destacou-se a importância do bioma Caatinga e do Rio Taperoá para a manutenção da vida das populações do Cariri paraibano, mais especificamente do município de São João do Cariri, a partir de ações de Educação Ambiental desenvolvidas com os docentes, visando que estes se tornem membros multiplicadores da necessidade de conservação de um ecossistema que se mostra tão sensível à ação antrópica.

\section{Considerações finais}

A necessidade de sobrevivência tem continuamente desafiado o homem a dar respostas às exigências da realidade apresentada por seu meio. As soluções que essa espécie tem encontrado não decorrem exclusivamente do natural e do instintivo. Como a própria vivência do homem comprova, o indivíduo não é um ser isolado, mas vive em sociedade (um atua sobre o outro, ambos transformando-se continuamente). Assim, as respostas por ele emitidas são também produtos da educação (daí a necessidade de se educar para transformar, desenvolver, participar) e da política (no seu sentido de opção, escolha, ação, compromisso e decisão). 
O processo educativo e as decisões políticas resultantes da consulta popular, do conflito de interesses e das práticas sociais podem levar todos os agentes sociais (população organizada, poder econômico, órgãos e instituições do poder público, comunidade científica e outros) ao compromisso para com a conservação, gerenciamento e recuperação do ambiente, no nosso caso o bioma Caatinga e a revitalização da Bacia Hidrográfica do Rio Taperoá.

Devido ao importante papel da educação na construção de uma nova sociedade, é indispensável, portanto, que se conheça o meio no qual esta vai se desenvolver. Quais são as características dos professores, dos alunos, da área física e social da escola? Quais são seus problemas? Quais são suas necessidades? Por meio dessas perguntas, compreenderemos a educação não como fonte e acúmulo de conhecimentos em si mesmos, mas como instrumento de capacitação e desenvolvimento de respostas criativas, responsáveis e libertadoras (atitudes políticas e medidas práticas) para com as exigências concretas da realidade e o enfrentamento dos problemas relacionados ao meio ambiente.

Se, a exemplo de Reigota (1998, p. 14), considerarmos o meio ambiente "o lugar determinado ou percebido, onde os elementos naturais e sociais estão em relações dinâmicas e em interação" e entendermos que essas relações "implicam processos de criação cultural e tecnológica e processos históricos e sociais de transformação do meio natural e construído", não poderá haver melhor laboratório didático para o ensino que o próprio meio ambiente e o conhecimento científico adquirido por essa mediação manter-se-á por muito mais tempo no indivíduo se for útil, do ponto de vista da relevância social, e se este se tornar um continum de aprendizagens ao longo de sua vida.

Nessa perspectiva, a escolha e a delimitação das atividades pedagógicas pelo professor são um requisito imprescindível no planejamento escolar. Certamente a elas precedem os objetivos do ensino, mas é através delas que os estímulos desencadeadores da aprendizagem se farão presentes no processo educativo. Quanto mais estímulos e quanto maior a aproximação com o objeto de estudo, maior e melhor será a aprendizagem das crianças e dos jovens, pois terão seus esquemas de assimilação mais ativamente desenvolvidos. 
Os professores envolvidos se manifestaram bastante receptivos e participaram, efetivamente, do processo de investigação proposto. Os relatos registraram e apontaram as preocupações pedagógicas e teóricas referentes às questões ambientais, revelando as dificuldades para tratar temas que emergem no cotidiano das pessoas na comunidade e que chegam à escola através dos alunos.

Os relatos mostraram também que os professores reconhecem a necessidade da implementação de ações voltadas à conservação ambiental, porém, sentem-se inseguros para tratarem dessas questões no dia a dia pedagógico. Contudo, as experiências têm demonstrado que a repercussão das atividades é bastante positiva e já se percebe (em diálogos informais) a aplicabilidade das orientações elaboradas nas oficinas pedagógicas e cursos em muitas práticas educativas no contexto da sala de aula nas escolas do município de São João do Cariri, tais como a elaboração de capítulos de livros e artigos, em conjunto com os professores, a produção de cordéis, textos e poemas pelos alunos, orientados pelos professores, e a produção de um acervo de materiais didáticos (modelos tridimensionais, jogos, fantoches, etc.), os quais estão sendo utilizados nas práticas educativas dos docentes.

A interferência educativa nas comunidades, através da escola, é uma necessidade premente, considerando a carência teórica que se evidencia nos discursos dos professores e a "obrigação" ética que os pesquisadores têm de socializar com a comunidade todos os conhecimentos gerados a partir de estudos que são desenvolvidos nessas áreas.

\section{Agradecimentos}

Ao Projeto PELD/CNPq Bioma Caatinga: estrutura e funcionamento e ao Projeto Universal/CNPq pelo apoio financeiro. Aos professores da educação básica do município de São João do Cariri, principalmente ao prof. Nivaldo Maracajá, pela inestimável colaboração e receptividade à nossa equipe. 


\section{Referências}

ABÍLIO, Francisco José Pegado. Educação Ambiental: formação continuada de professores no Bioma Caatinga. João Pessoa: EDUFPB, 2010.

ABÍLIO, Francisco José Pegado; CAMAROT'TI, Maria Fátima; SILVA, Rivete de Lima. Formação continuada de professores no cariri paraibano. In: ABÍLIO, Francisco José Pegado. Educação Ambiental: formação continuada de professores no Bioma Caatinga. João Pessoa: EDUFPB, 2010. p. 13-41.

ABÍllo, Francisco José Pegado; MARACAJÁ FILHO, Nivaldo; PEQUENO, Olga Hélia Cruz; GRANJEIRO, Zélia Tavares; ARAÚJO, Fabrícia Torreão; ALCÂNTARA, Hugo Morais; RAMOS, Maria Stela Maracajá Porto; RAMOS, Maria do Socorro Cordeiro; SAMPAIO, Marijane Ramos; ARAÚJO, Josileide Ferreira; CHARARA, Faruk Maracajá Napy; RUFFO, Thiago Leite de Melo; CAMAROTTI, Maria de Fátima; SILVA, Rivete Lima. Vivências integradoras de educação ambiental no contexto da educação básica. In: ABÍLIO, Francisco José Pegado. Educação Ambiental: formação continuada de professores no Bioma Caatinga. João Pessoa: EDUFPB, 2010. p. 111-144.

ABÍLIO, Francisco José Pegado; VILA, Alberto José Tabosa; ANDRADE, Alexandrina Maria Suassuna; MONTENEGRO, Ana Karla Araújo; GUERRA, Rafael Angel Torquemada. Meio Ambiente e Educação Ambiental: uma análise crítica dos Livros Didáticos de Ciências de Ensino Fundamental ( $5^{\mathrm{a}}$ a $8^{\mathrm{a}}$ séries) publicados no período de 1990 a 2004. In: ABÍLIO, Francisco José Pegado; GUERRA, Rafael Angel Torquemada (Org.) A questão Ambiental no Ensino de Ciências e a Formação Continuada de Professores de Ensino Fundamental. João Pessoa: EDUFPB/FUNAPE/LEAL, 2005. p.63-78.

ABÍLIO, Francisco José Pegado; GUERRA, Rafael Angel Torquemada. A temática ambiental no ensino de Ciências: um projeto de formação continuada de professores de ensino fundamental do Município de Cabedelo-PB. In: CONGRESSO INTERNACIONAL DE FORMAÇÃO CONTINUADA E PROFISSIONALIZAÇÃO DOCENTE, 1., 2005, Natal. Anais... João Pessoa: EDUFPB, 2005a. p. 520-521.

ABÍLIO, Francisco José Pegado; GUERRA, Rafael Angel Torquemada (Org.). A questão ambiental no ensino de Ciências e a formação continuada de professores de ensino fundamental. João Pessoa: EDUFPB/FUNAPE, 2005b. 
BEZERRA, Tatiana Marcela de Oliveira; GOLÇALVES, Andréa Aparecida Cajueiro. Concepções de meio ambiente e educação ambiental por professores da Escola Agrotécnica Federal de Vitória de Santo Antão-PE. Biotemas Trindade, v. 20, n. 3, p. 115-125, 2007.

BRASIL. Ministério da Educação. Secretaria de Educação Fundamental. Parâmetros Curriculares Nacionais: terceiro e quarto ciclos - apresentação dos temas transversais, Brasília, DF: MEC/SEF, 1998.

- Lei $\mathrm{n}^{\circ} 6.938$ de 31 de agosto de 1981. Dispõe sobre a política nacional do meio ambiente, seus fins e mecanismos de formulação e aplicação, e dá outras providências. Diário Oficial da República Federativa do Brasil, Brasília, 1981. Disponível em: <http://www.planalto.gov.br/ccivil_03/Leis/L6938.htm>. Acesso em: 10 abr. 2010 .

Lei $n^{\circ}$. 9.394, de 20 de dezembro de 1996. Estabelece as diretrizes e bases da educação nacional. Diário Oficial da República Federativa do Brasil, Brasília, $1996 . \quad$ Disponível em: < http://www.planalto.gov.br/ccivil_03/Leis/L9394.htm> Acesso em: 09 mar. 2009.

- Lei $\mathrm{n}^{\circ}$ 9.795, de 27 de abril de 1999. Dispõe sobre a educação ambiental e institui a Política Nacional de Educação Ambiental e dá outras providências. Diário Oficial da Republica Federativa do Brasil, Brasília, 1999. Disponível em: <http://www.planalto.gov.br/ccivil/Leis/L9795.htm> acesso em: 09 abr. 2009.

CARNEIRO, Sônia Maria Marchiorato. A Educação Ambiental e a formação de educadores: pesquisas em escolas do ensino fundamental. In: GUERRA, Antonio Fernando S.; TAGLIEBER, José Erno (Org.). Educação Ambiental: fundamentos, práticas e desafios. Itajaí: Univali, 2007. p. 183-196.

CASTRO, Rodrigo; REED, Philip; SALDANHA, Marcela; PRADO, Flávia do; FERREIRA, Maria Valnete; OLIVEIRA, Marcelo. Reserva Natural Serra das Almas: construindo um modelo para a conservação da Caatinga. In: BENSUSAN, Nurit; BARROS, Ana Cristina; BULHÕES, Beatriz; ARANTES, Alessandra (Org.) Biodiversidade: para comer, vestir ou passar no cabelo? São Paulo: Peirópolis, 2006. p. 77-80. 
DIAS, Genebaldo Freire. Um grande desafio: dimensões humanas das alterações globais. In:

São Paulo: Gaia, 2003. p.243-254.

(Org.). Educação Ambiental: princípios e práticas.

GADOTTI, Moacir. Pedagogia da Terra. São Paulo: Peirópolis, 2000.

GASQUE, Kelley Cristine Gonçalves Dias; COSTA, Sely Maria de Souza. Comportamento dos professores da educação básica na busca da informação para a formação continuada. Ciência da informação, v. 32, n.3, p. 54-61, 2003.

GIL, Antonio Carlos. Métodos e Técnicas de Pesquisa Social. 5. ed. São Paulo: Atlas, 1999.

GUERRA, Rafael Angel Torquemada. A educação ambiental numa escola pública: erros e acertos de uma caminhada. In: PEDRINI, Alexandre de Gusmão (Org.). Metodologias em Educação Ambiental. Petrópolis: Vozes, 2007. p.126-146.

GUERRA, Rafael Angel Torquemada; ABÍLIO, Francisco José Pegado. Meio Ambiente e Educação Ambiental: formação continuada de professores de Ensino Fundamental do Município de Pitimbu, PB. In: CONGRESSO INTERNACIONAL DE FORMAÇÃO CONTINUADA E PROFISSIONALIZAÇÃO DOCENTE, 1., 2005, Natal. Anais... João Pessoa: EDUFPB, 2005. p.513-514.

GUERRA, Rafael Angel Torquemada; ABÍLIO, Francisco José Pegado. Educaşão Ambiental na Escola Pública. João Pessoa: Foxgraf, 2006.

LEAL, Inara R.; TABARELLI, Marcelo; SILVA, José Maria Cardoso da. Ecologia e Conservação da Caatinga. Recife: UFPE, 2005.

LIMA-E-SILVA, Pedro Paulo de; GUERRA, Antonio J. T.; MOUSINHO, Patricia; BUENO, Cecília; ALMEIDA, Flávio G. de; MALHEIROS, Telma Maria Marques; SOUZA JÚNIOR, Alvaro B. de (Org.). Dicionário brasileiro de ciências ambientais. Rio de Janeiro: Thex, 2002.

LOZANO, Marcia da Silva; MUCCI, José Luiz Negrão. A educação ambiental em uma escola da rede estadual de ensino no município de Santo André: análise situacional. Rev. eletrônica Mestr. Educ. Ambient., v. 14, n. 1, p. 132-151, 2005. 
MANZANO, Maria Anastácia; DINIZ, Renato Eugenio da Silva. A temática ambiental nas séries iniciais do Ensino Fundamental: concepções reveladas no discurso de professoras sobre sua prática. In: NARDI, Roberto, BASTOS, Fernando; DINIZ, Renato Eugenio da Silva (Org.). Pesquisas em Ensino de Ciências: contribuições para a formação de professores. São Paulo: Escrituras, 2004.

MARCONI, Marina de Andrade; LAKATOS, Eva Maria. Metodologia Cientifica. São Paulo: Atlas, 2004.

MENDES, Benedito Vasconcelos. Biodiversidade e Desenvolvimento Sustentável do Semi-Árido. Fortaleza: SEMACE, 1997.

MENEZES, Luís Carlos de. Características convergentes no ensino de ciências nos países ibero-americanos e na formação de seus professores. In: (Org.). Formação continuada de professores de Ciências no âmbito iberoamericano. Campinas: NUPES, 2001. p.45-58.

MOREIRA, Daniel Augusto. O Método Fenomenológico na Pesquisa. São Paulo: Pioneira Thomson Learning, 2004.

PASSOS, Luiz Augusto; SATO, Michèle. De asas de jacarés e rabos de borboletas à construção fenomenológica de uma canoa. In: SATO, Michèle; CARVALHO, Isabel Cristina de Moura. (Org.) Educação Ambiental: pesquisa e desafios. Porto Alegre: Artmed, 2005. p.45-58.

PENTEADO, Heloisa Dupas. Meio Ambiente e Formação de Professores. São Paulo: Cortez, 2000.

PEREIRA, Marsílvio Gonçalves; GUERRA, Rafael Angel Torquemada. A temática ambiental na educação escolar: tecendo fios e vencendo desafios na construção de saberes e fazeres. In: PEREIRA, Marsílvio Gonçalves; AMORIM, Antonio Carlos R. (Org.). Ensino de Biologia: fios e desafios na construção de saberes. João Pessoa: EDUFPB, 2008. p.171-198.

REIGOTA, Marcos. Meio Ambiente e Representação Social. São Paulo: Cortez, 1998. (Coleção Questões da Nossa Época, v. 41).

SATO, Michèle. Apaixonadamente pesquisadora em educação ambiental. Educação Teoria e Prática, Rio Claro, v. 9, n. 16-17, p. 24-35, 2001. 
SATO, Michèle; PASSOS, Luiz Augusto. Biorregionalismo: identidade histórica e caminhos para a Cidadania. In: LOUREIRO, Carlos Frederico Bernardo; LAYRARGUES, Philippe Pomier; CASTRO, Ronaldo Souza de (Org.) Educação Ambiental: repensando o espaço da cidadania. São Paulo: Cortez, 2002. p. 221-252.

SAUVÉ, Lucie. Educação Ambiental e Desenvolvimento Sustentável: uma análise complexa. Revista de Educação Pública, Cuiabá, v.6, n.10, p.72-102, 1997.

- A educação ambiental: uma relação construtiva entre a escola e a comunidade. Montréal: Projeto EDAMAZ, UQAM, 2000. Disponível em $<$ http://www.ufmt.br/ gpea/pub/edamaz-livro.pdf $>$. Acesso em: 30 jun. 2006.

Uma cartografia das correntes em educação ambiental. In: SATO, Michèle; CARVALHO, Isabel Cristina de Moura (Org.) Educação Ambiental: pesquisa e desafio. Porto Alegre: Artmed, 2005. p. 17-44.

SEGURA, Denise de Souza Baena. Educação Ambiental na Escola Pública: da curiosidade ingênua à consciência crítica. São Paulo: Annablume/FAPESP, 2001.

TRAVASSOS, Edson Gomes. A prática da Educação Ambiental nas Escolas. Porto Alegre: Mediação, 2006.

ZABALA, Antoni. A prática educativa: como ensinar. Porto Alegre: Artmed, 1998.

Artigo: recebido em 14/05/2010 - aprovado em 22/12/2010 